induces a sense of chilliness. The appetite is fairly good. The tongue was slightly coated and dry. The teeth are stained black. Sleep is good and refreshing. Rarely there is headache, which when present is supra-orbital and vertical. Occasionally there is vertigo. On inclining the body forward and flexing the trunk after meals vomiting results. Sometimes, it was reported, food returns without entering the stomach. The patient is annoyed by a sense of the presence of hair in the throat. She has never had a convulsion or lost consciousness. She suffers a good deal from flatulence, which sometimes precedes a diarrheal discharge.

The patient appears quite unable to walk unsupported. When asked to make the attempt she throws her arms about herself rather incoördinately and sways upon her feet. She is unable to stand at all with her feet together. She maintains that the right leg feels heavy. She can walk up and down stairs with the aid of the banister. She volunteers the information that she does not fall when her feet are warm, and that she does not topple over in her own room. The knee-jerks are greatly exaggerated and ankle clonus is represented by a few contractions of the foot upon flexion. So far as can be determined there is no other derangement of motility and the muscles used in walking and standing possess the power of performing other acts. Sensibility appears generally preserved. The right pupil is a little smaller than the left; both are regular and react to light. The patient is rather pallid and of poor nutrition.

With great preciseness the patient related, as she did all the details of her case, that she had suffered from three shocks, one on Jan. 30, 1894, in which she lay helpless, though conscious, for half an hour: a second on Jan. 1, 1895, in which the same condition persisted for an hour and a half; and a third on Feb. 10, 1896, lasting for ten hours. She subsequently recalled that she had a fourth attack on Feb. 15, 1896, lasting for twenty hours. The patient has also at different times passed unusual substances from the bowels; on one occasion what she describes as a kind of tube; on others small white bodies looking like eggs, also hairs; again something resembling a small animal supplied with many feet: on still another occasion something having a white head and black eye. Two specimens of such substances submitted to me as having been passed, respectively, Nov. 20 , 1894, and March 29, 1896, presented gross and microscopic appearances of vegetable fiber.

After taking a pill of aloes and asafetida for several days the patient found that she always fell backward whenever she approached a receptacle containing water. She pointed out a small spot as large as a pinhead upon the left ear which for two or three months has from time to time been the seat of intense burning. She stated further that a sister with whom she slept for a time had suffered from cold feet and she wondered if she might not have derived the coldness of her own feet from that circumstance.

The patient is extremely detailed in her account of herself, and in this she is ably supported by her hus band, who supplements by suggestion or otherwise such facts as the patient herself may have failed to mention. At times they may differ in their respective versions, but altogether they are quite in accord.

The case impresses itself upon me as clearly an hysterical one, all of the symptoms and attendant cir- cumstances, including the family history, supporting such an opinion. It must none the less be viewed with a good deal of seriousness and the prognosis must be guarded. If the patient could be removed from her present surroundings, if the current of her life could be entirely changed, the prospect might be more hopeful. This case and allied ones can not be viewed as a manifestation of merely functional disturbance. It is far more probable that there have taken place nutritional changes, which become more and more pronounced with the progress of the case, and which in time may lead to structural alterations. When only the nutrition of the nervous system suffers the prognosis is good under favorable conditions, but when changes in structure have resulted permanent and perfect cure is beyond the range of hope.

\section{REPORT OF THREE CASES OF POLYMYO. SITIS ACUTA; WITH REPORT OF POST-MORTEM ON ONE CASE.}

BY J. BAILLIE KELL, A.M.,M.D.

LATE CHIEF SURGEON ESPAFNOL AMERICAN STEAMSHIP COMPANY. BARNHILL, OHIO.

The report of a case of polymyositis acuta, by Dr. J. B. Herrick, in the Americum Journal of the Medical Sciences for April 1896, and his reference therein to the literature of the subject especially as to its bearings upon its etiology and the evident interest taken by the profession, relative to this feature of these cases, leads me to make the following brief report, which I take in the form of an abstract from my individual case report book, of the history of three cases, occurring simultaneously in the same locality, of what $I$ at the time considered typical cases of polymyositis acuta. Subsequent study and observation of this class of cases have only tended to confirm the diagnosis made at the time. One of these cases terminated fatally within seven days after my attention was first drawn to the patient's condition; the remaining two terminated in a rapid convalescence and uninterrupted recovery. Most observers of this morbid condition have held it to be of an infectious origin, the case reported by Senator, ${ }^{1}$ being of especial interest, where the patient was affected following the ingestion of stale crabs. Hitherto all efforts at isolating any specific organism or germ to account for the manifestation of this disease have proven futile; but the history of the cases I am about to relate makes it appear, that it is certainly due rather to a certain infective specific entity, in all probability belonging either to the class of toxin or to the gregarina. If there be anything of a contagious nature about these cases, then surely the conditions under which my cases developed, and ran their course, would certainly have had a tendency to produce the same disease in other members of the same group of men numbering forty-four who occupied the same sleeping quarters with these men all through the duration of their illness.

The histories of these cases are briefly as follows: In the month of .July, 1893, the writer, while in the employ of a steamship company engaged in the New York, Cuban and Mexican trade, in the capacity of surgeon of a large 8,000 ton steel steamer, with one hundred and seventy-five firemen, coal-passers and

Senator: Leber acute und subacute multiple neuritis und myo sitis, Zeit. für Klin. Med., 1888, XV: and Ueber acute poly rnyositis und neuromyositis. Deut. Med. Woch., 1893. 
water-carriers, exclusive of non-commissioned and commissioned officers on board, was lying in the closely land-locked harbor of Havana, Cuba. Two or three days after we had come to anchor, the first officer of the vessel, notified me, that one of his men was ill, and asked me to go to the fore-castle and examine him. I did so. On reaching that part of the ship I found two men, instend of one ill, of which the following are the brief histories:

Case 1.-A. M., aged 23 years, a native of Saroy, France, states that last night on retiring to his bunk, and just as he was in the act of stretching out his limbs after reaching the recumbent posture, he felt a sharp, sudden stinging pain in the calf of his right leg as though he had been bitten by a spider. As we had been engaged during the day in loading the vessel's hold with bananas in the bunch, visions of huge centipedes came before him, and he very hurriedly kicked off his blanket and got out of the bunk to look for the insect, but failed to find any evidence of its presence, and a close inspection of the limb in the region of the pain, failed to disclose any wound, such a would be made by the bite of a centipede or any one of the several large and poisonous insects that live in this semi-torrid region. Feeling considerably relieved, he returned to his bunk and went to sleep, awaking about mid-night suffering with considerable dyspnea and pain in the left pectoral and cardiac area, the pain darting in short sudden stabs from the apex region around the chest to a point below the inferior angle of the left scapula. No disturbance of the stomach or bowels was present, while the kidneys acted normally throughout the illness. Upon examination the following day at 9 A.M. I found the right leg markedly swollen in the region just inferior to the popliteal space, the skin giving an edematous, harsh, branny sensation to touch, while upon the cutaneous surface was an eruption having features of both measles and an urticaria. This eruption was found on both extremities but only upon the flexor surface. A careful examination of the chest revealed some moist bronchial râles, the remnant of an old bronchitis ; but otherwise the respiratory murmur was normal. Great interest was attached to the heart; percussion revealed the fact that the apex beat was removed at least an inch and a half farther to the left than was normal, while auscultation showed that the heart muscle was undoubtedly involved in some morbid process. The first and second sounds of the heart were strangely blended, instead of either being at all distinct, they gave forth a combined booming sound and reminded me more strongly than any other sound I had ever heard of a vessel upon the high sea, firing a salute with her big guns at a distance of from six to eight miles. The individual sounds were very in distinct and yet the combined murmur was at least three times as voluminous as it should have been. This sound was transmitted a great distance up the arterial system ; I could distin guish it plainly in the carotid vessels and also in the subclavian, and here the sound had precisely the same characters as when heard in the cardiac area as though the sound was transmitted through a non-conductor of sound. The heart's pulsations in the erect posture was 120 , in the recumbent 100 per minute. No apparent irregularity was noticeable. The pupils reacted to light normally, while the tendon reflex was slightly exagger ated. Ankle clonus was present also to a certain extent None of the lymph glands were enlarged, and the patient denying any specific history, a thorough search failed to reveal any evidence of an old sore. Abdominal examination revealed a slightly enlarged spleen and liver, the latter though to a very small extent. Examination of bladder, rectum and prostate revealed them in a normal condition. Six hours later I saw the patient again, his left forearm was now involved, and if anything far more painful than the affected leg. Here especially the supinator longus and pronator radii teres were affected, the bellies of these muscles were badly swollen. while the skin covering them had the same edematous, hard, branny feeling to the sense of touch, as that on the leg. As the supinator approached its tendinous insertion, it was seen to be swollen to at least three times its normal volume, and so exceedingly painful was pressure of any kind on the affected leg, chest and arm, that the patient even dispensed with a blanket for covering his person, he stating that its weight produced pain. At this time I excised a small portion of the supinator longus for microscopic examination, which under the lens presented the usual evidences of acute muscular inflammatory action. Muscle striation had almost and in some places completely disappeared, while the individual muscle fiber were many of them greatly swollen, and presented, some a granular condition, others a hyaline degeneration. Between the muscle fibers could be seen many large cells with large nuclei, believed to be proliferation cells; the blood vessels of the part seemed to be greatly en. larged, in some localities presenting evidences of a developing periarteritis. In one place could be seen a white blood corpuscle engaged in the emigratory act, passing through the ves sel wall, into the surrounding inter-fibrillary spaces. All efforts along the line of forming cultures from the fluid exuded by pressure from the muscle sections were absolutely futile, resulting in each instance negatively.

As it is a notorious fact, that sailors and others leading a seafaring life, live almost exclusively upon pickled and salted pork, hence a very carcful search was made for trichinæ, but resulted negatively. This man continued to grow worse, until owing to pressure paralysis of the palato-pharyngeal muscles, he was unable to swallow, even liquids returning through his nose on attempting deglutition. His temperature remained throughout his illness, which was of six days duration, at about 100 degrees $\mathbf{F}$, except just previous to his death, when it rose instantly to 106 degrees. The patient gradually progressed from bad to worse, until death came to his relief, apparentily due to paralysis of the respiratory muscles.

Post-mortem, ten hours after death: Body well developed and nourished; considerable hypostatic congestion. Eruption on skin has totally disappeared: abdominal adipose abundant. Brain is in a normal condition; venous simuses full of blood; lungs nil. Heart muscle found to be greatly swollen, the thickness of its muscle being greatly increased. Microscopic sections of cardiac muscle, intercostals, supinator longus, pronator and gastrocnemius, revealed simply the same patholgic conditions as were found in the examinations of the muscle section removed from the supinator previous to death. The stomach. liver and bowels were normal in appearance; the spleen was markedly enlarged and considerably softened. Sections of it placed under the lens, revealed a vast number of lencocytes far beyond the number usually found in the spleen in health; the parenchyma of the spleen also presented a granular and in some locations, a hyaline degeneration. Periarteritis was also a prominent feature of the pathology of the spleen. The bladiler, rectum, prostate gland and associated glands presented no deviations from the usual normal condition. Death in this case was undoubtedly caused by paralysis of the respiratory muscles, caused by an erdargement in their bulk, to the degree that the ensuing pressure caused a paralysis. I have stated that all efforts in the direction of isolating a germ or special forms of bacteria to account for the disease by cultures or gelatin or agar, resulted in a failure, so after death was if likewise in sereral separate experiments made with the tissues and the juices expressed from the cut sections from six different locations. While it is doubtless due to the presence in the blood of either a toxin or one of the different forms of gregarina, the various methods of precision which science has placed in our hands to date, are not sufficiently efficient to demonstrate their presence in the tissues or the blood.

Case $2 .-$ At the same time that I was called to see A. M. I found B. F., aged 26 years, an American by birth, lying in his bunk, groaning considerably from pain in the region of the hip. Upon examination I found the right gluteal region greatly increased in size; the cutaneous surface had the same tense, hard edematous feeling that was found in A.M.'s case. A markedly papular eruption soon developed upon the right buttock; this swelling and eruption gradually extended to the extent of three inches below the major trochanter. Five hours after first seeing this patient I cocainized a small area in the affected region, and removed a small piece of the gluteus maximus muscle. Upon making the incision into the muscle a quantity of sanguinous fluid, approaching two drams in amount, poured fourth from the cut section. This I managed to collect in a small porcelain spoon, previously rendered aseptic. The muscle was deeply injected and well vascularized. Under the microscope this section of muscle 
presented the same features as the section taken from $A$. M.'s case, only that the number of polynuclear cells was much larger, while the individual muscle fiber was far more granular in appearance, and in several localities the part presented simply the detritus of a previously preëxisting muscle fiber. Efforts at isolating germ life or bacteria upon either gelatin or agar resulted fruitlessly as they did in the previous case. Under the application of an active embrocation and iodid of potassium internally, the disease gradually disappeared, and in a few days the patient was as well as usual. I will add that this patient utterly denied all history of syphilis, and as he presented no signs of adenopathy his statement must be accepted,

Case 3.-..S. S., aged 27 years, an Englishman by nativity was almost precisely similar to Case 2, except in so far that the location of the inflamed muscle is decidedly different. This case did not develop until after twenty-four hours had passed after the previous cases were brought to my notice. The next afternoon following the day on which I saw the first :two cases, the second officer called my attention to this man, saying his feet were swollen so badly he was unable to get his shoes on. I immediately went to see him and found his right foot badly swollen, especially just anterior to the tarsal arch. Here the tendons which can usually be so easily distinguished in this portion of the human anatomy, were swollen to the size of whip-cords, each tendon being at least one-third of an inch in diameter beyond its normal size. The movements of extension and flexion of the toes were greatly circumscribed and decidedly diminished, and any movement along this line gave rise to great pain, the patient crying out and resisting actively when I volunteered an effort at flexion and extension myself. The eruption was exceedingly characteristic in this patient. In some places could be seen the papulous eruption of a bluish coloration, such as is of ten seen in measles, while in other places would be found the large semi-circular, crescentic wheals so often found in urticaria. In two places only did I succeed in finding any of the eruptions which had progressed to the vesicular stage, and I was very careful to withdraw their contents, with a hypodermic syringe, previously rendered perfectly aseptic, for the purpose of ascertaining whether they contained any germ life. All work along this line resulted as all previous efforts in this direction had done the fluid proving to be perfectly sterile without any evidence of germ life whatever.

What I have observed in these three cases, but other witnesses are silent on, so far as I can ascertain, is as to the site of the eruption. Invariably in these three cases the eruption was found upon the flexor surfaces of the limbs, and even when the pain would extend to the extensor surfaces and muscles, the eruption did not present itself in these situations. Whether this is because of the well-known anatomic fact that the cutaneous structure is much more delicate and thiner on the flexor that the extensor surface, I can not venture to assert. That it is true, is attested by the histories herewith given of the three cases.

Causation: The causation of these three cases has always been held to be very obscure. Senator, ${ }^{1}$ quoting Herrick, says: "Three liypotheses can be advanced as to its cause: 1 , that it is due to a specific microörganism (vegetable parasite); 2 , that it is due to a chemic poison (toxin): 3 , that it is due to an animal parasite (gregarina)." In investigating the causes of the three cases presented above, the sanitary conditions of the city of Havana, and its closely land-locked harbor must be considered. Here is a city of 330,000 inhabitants, the poorer class of which are extraordinarily filthy in their habits and manner of living, with yellow fever an epidemic at the time referred to within the confines of the city, the registrar of vital statistics reporting a daily mortality of from fifteen to twenty deaths: while in addition to these there could be added thereto dozens of deaths occurring each week from the pernicious forms of malarial fevers. Typhoid fever was at this time especially

2 Herrick, Dr. J. B.: Polymyositis Acuta, American Jour. Med. Sciences, April, $189 ;$, p. 414. fatal throughout the entire island, following the encampments especially of the newly arrived Spanish soldiers. As is well known, all of the large sewers which carry off the excrementitious discharges from this populous city discharge their contents directly into the waters of the harbor, and the latter being virtually land-locked, having but one mode of ingress and egress, viz., a small channel not many yards in width between Moro Castle and the Fortress of Cabaniss. The amount of current which flows in and out with the flow and ebb of the tide is very small indeed. While there is some removal of the immense amount of excreta that is cast into the harbor each twenty-four hours, nevertheless a sufficient amount remains to be decidedly instrumental in developing yellow fever and other forms of malignant fever, as the history of the fever-ridden city of Havana ever since the year 1600 fully attests. Hence if this infected water will so affect the inhabitants who live on the shore close to its confines, what of the finny inhabitants who have their homes in the coral caverns in the deep bottom of this bay? On several occasions when our steamer had been anchored in toward shore, in close proximity to the mouth of one of the large sewers, I have observed different shoals of fish swimming along lazily close to the surface of the water, being apparently narcotized by some poisonous element in the water, as on casting an object toward them which ordinarily would cause them to instantly disappear, they would pay no attention to it whatever. It has been a habit with mariners and sailors while in this and various Mexican ports to eatch fish. and by thus giving them a change of diet, the catch would form a very welcome addition to their mess. Upon the day previous to my being called to see the first of these three cases, A. M. succeeded in killing a large, twelve-pound red snapper that was floating in an apparently aimless manner close to the port opening. After stunning the fish with a blow he had no difficulty in hooking it with a pole-hook and drawing it aboard. Securing his prize, he cleaned it carefully and invited the other two individuals who were affected to assist him in disposing of the catch. That this fish was undoubtedly ill when struck and killed, anyone at all conversant or familiar with the habits of that denizen of the deep water known as the red snapper, will fully realize. As a rule, this fish rarely if ever approaches nearer the surface than six or eight feet, even though food in the form of bread and meat be thrown to them from the ship's deck. They will seldom dash to the surface and grab the morsel as will the more bold and fearless sea bass but will rather wait until the natural weight of the food causes it to descend to their level. It is so well known among sailors that the red snapper is a difficult fish to take that when a man is successful in catching one he is usually envied by his comrades. What was the physical condition of this fish? This is a question which in the abscence of all parts of the piscine body, which had we preserved but a small portion, a microscopic section, several cultivations might have revealed some pathologic condition with special features, resulting in the isolation of a specific bacteria or some new form of germ life previously undescribed and unobserved, and would thus have provided us with a rational explanation of the morbid condition found in these men. The fish was probably narcotized by the ingestion of some of the poisons thrown out with the sewer discharges, whether this special poison 
belonged to the class of toxins or to that of the gregarina, it is certainly difficult to say. That it is true that the morbid condition found in these three cases was due to the ingestion of particles of this fish is evident from the fact that no more nor no less than the number which ate of the fish were affected. while forty-four other men all subjected to the very same conditions of daily life as those affected and occupying the same compartment with them as sleeping quarters, remained during the entire voyage utterly free from any contagion or infection.

\section{ABDOMINAL HYSTERECTOMY FOR FIBROIDS OF THE UTERLS.}

BY FRANKLIN H. MARTIN, M.D.

PROFESSOR OF GYNECOLOGY POST-GRADUATE MEDICAL SCHOOL, SURGEUN TO WOMAN'S HOSPITAL. CIIICAGO.

HISTORY.

Dr. Gilman Kimball of Lowell, Mass., was the first to deliberately plan and execute an abdominal hysterectomy for fibroids of the uterus. The operation was performed in August, 18533. On .June 25 of that year, Dr. Walter Burnham of the same city removed a portion of the uterus for this disease. Ten years later, December 19, 1863, Koeberle did his first hysterectomy for fibroids, with external fixation of the stump of the uterus. He employed a metallic ligature with a special device for tightening it. Péan soon followed Koeberle and supplementing the latter's work by the free employment of forci-pressure, and by publishing a systematic technique, which included the employment of steel pedicle pins over the metallic ligature for maintaining the pedicle extra-abdominally: his name became inseparably associated with hysterectomy by the extra-peritoneal method. Dr. M. M. Latta, Goshen, Ind., completed abdominal hysterectomy by tying the broad ligaments in sections down to vagina .July 6,1876 . The elastic ligature for temporary ligation was first employed by Kleeberg, of Odessa, July, 8, 1878. In August, 1878, Martin recommended the provisional elastic ligature. Hegar about the same time recommended the elastic ligature for permanent intraabdominal ligation of the pedicle.

In the evolution of abdominal hysterectomy many methods have been adopted and at different times each have had their advocates. The yearning for perfection has made confusion, owing to great efforts in many directions. In the early history of the operation the best results came with the extra-peritoneal method of treating the stump. This continued until the last few years when, with improved technique, greater experience, and to avoid unpleasant sequela the pendulum is irresistibly swinging toward the intraabdominal pedicle. The history carries us through the following methods: 1, extra-peritoneal or Péan's; 2 , intra-peritoneal or Schroeder's; 3, complete hysterectomy or Eastman's; 4, vaginal fixation or Byford's; 5 , ligation of arteries outside of uterine tissue with intra-peritoneal stump or Stimpson-Baer method.

1. Extra-peritoneal Method.-The extra-peritoneal method as originally carried out by Péan, consisted in clamping the neck of the tumor with a wire clamp or serre-noud including the broad ligaments with the appendages, preventing slipping of the constrictors with pedicle pins, excising of the tumor, fixation of the pedicle in the lower angle of the abdominal wound, and closure of the abdominal wound closely down to the stump. Joseph Price of this country has improved this method until it is well-nigh perfect.. His success with it has been phenomenal.

Hegar and Kallenbach modified it by carefully securing the pedicle after Schroeder's method and uniting it in the abdominal incision extra-peritoneally but beneath the closed incision.

Kelly and independently Van de Walker modified it by making temporary fixation, like Péan, until liability to hemorrhage had ceased, when the wire was removed and the pedicle allowed to contract into abdominal incision.

2. Intra-previtomeal Method.-This, as practiced by Schroeder, consisted primarily in constricting the pedicle with the Kleeberg rubber band, removing the tumor, paring down the stump, taking from its center a wedge-shaped piece of the bulky tissue, cauterizing the canal, closing the stump by strongly sewing together the edges of the wedge-shaped incision and finally sewing over all the peritoneal edges. The stitching of the stump was intended to be secure enough so that all subsequent oozing was made impossible after the final removal of the rubber ligature. The pedicle was then dropped, as is the pedicle after ordinary ovariotomy, and the abdomen closed.

This method was modified by Olshausen, Charles T. Parkes, Zweifel, Hofmeier and others.

(a) Olshausen modified by securing the pedicle with a rubber ligature, and sinking the whole by sewing over it the peritoneum.

(b) Charles T. Parkes modified it by ligating firmly with strong silk and cauterizing the tissues of the pedicle to firm bone-like condition with the actual cautery over a temporary clamp.

(c) Zweifel tied the pedicle firmly with a strong multiple ligature of silk, securing it in this manner in several parts.

(d) Marcy of Boston, 1881, secured an intraabdominal stump by sewing from the outer edge of one broad ligament to the other with thirteen cobbler's stitches; including in the process ovarian arteries, broad ligaments, uterine arteries and the stump of the uterus formed by the cervix uteri.

(e) Hofmeier carefully ligated the pedicle in its circumference without closing the cervical canal, and closed its abdominal end by covering with peritoneum. Drainage could take place into the vagina through the patulous canal.

(f) Goffe and Albert independently employed treatment similar to Hofmeier's, with the addition of applying a capillary drain through the open cervix into the vagina.

3. Complete Remoral, Eastman's methods.

(a) In 1888 Dr. Mary A. D. Jones removed the entire uterus, including the cervix, by employing long hemostatic forceps for the lower portion of the broad ligament, and severing the cervix from the vagina.

(b) Joseph Eastman's method, 1889: The broad ligaments are tied off, including the appendages, the vagina opened posteriorly by elevating it by means of a special staff constructed for the purpose, which is held by an assistant, the vaginal edges are ligated with long ligatures which afterward serve to invert the edges into the vagina, and the cervix and stump progressively cut away. The peritoneum is sewed over the inverted vaginal edges, the abdominal wound is closed, and the vagina packed with gauze. The mass of the tumor, if cumbersome, may be cut away, previous to opening the ragina, by putting on a temporary rubber ligature. 